\title{
S-clasp with Apron Spring: A Single Tooth Crossbite Correction in Mandibular Arch
}

\author{
Lakshay Mihani ${ }^{1}$, Siddharth Mehta ${ }^{2}$, Vidur Goyal ${ }^{3}$, Kamal Bajaj ${ }^{4}$, Esha Nagpal ${ }^{5}$, Kimi Mittal ${ }^{6}$
}

\begin{abstract}
Posterior crossbite is one of the most prevalent malocclusions in the primary and early mixed dentition. Different techniques have been used to correct anterior and posterior crossbites in maxillary arch, for example quad helix and removable appliance with expansion screw. This article aims at correcting the single tooth crossbite in mandibular arch in cases where the mandibular molar is buccally positioned by a modified appliance, which includes a modified clasp and an apron spring that helps in correcting the abovementioned problem.

Keywords: Clasp, Crossbite, Mandible, Removable, Spring.

Journal of Mahatma Gandhi University of Medical Sciences \& Technology (2019): 10.5005/jp-journals-10057-0113
\end{abstract}

\section{INTRODUCTION}

Posterior crossbite is a malocclusion frequently seen in the deciduous and mixed dentitions ( $8 \%$ and $22 \%$, respectively). ${ }^{1-4}$ It can be unilateral or bilateral and might develop during the mixed dentition. ${ }^{3,5,6}$

The etiology of this malocclusion can be dental, skeletal, or functional alone or in combination. The most common form of posterior crossbite is unilateral with functional shift of the mandible toward the crossbite side. Unilateral posterior crossbite might be associated with mandibular displacement. Some reports suggest that posterior crossbite might increase the risk of later temporomandibular joint dysfunction; however, other studies found this association weak and inconsistent. ${ }^{7-10}$ Early treatment of posterior crossbites by means of maxillary expansion is currently advocated to redirect the erupting teeth into their normal positions and to eliminate premature occlusal contacts, thereby favoring beneficial dentoskeletal changes during growth periods. ${ }^{6,11,12}$

\section{FABRICATION}

- First take a 21/-22-gauge round stainless steel wire and straighten the wire.

- Then take a 0.016 round stainless steel wire to make a spring which is incorporated into the straight wire (Fig. 1).

- Measure the width of the mandibular first molar and do the markings on 0.016 round stainless steel wire both mesial and distal to the molar.

- Then give $90^{\circ}$ bends on both the ends gingivally and then make coils on both the ends (Fig. 2).

- Then incorporate this spring into the straight wire and solder it at an angle of $45^{\circ}$ to the tooth long axis.

- Then do the marking on the straight wire mesial to second premolar and distal to second molar by placing the wire at gingival level of the teeth.

- Then give a $90^{\circ}$ bend toward the gingival embrasure between first and second premolar and other $90^{\circ}$ bend toward the gingival embrasure between first and second molar (Fig. 3).

- After that the clasp is adapted such that it takes an S form and adapted occlusally, and then retentive tags are given lingually (Figs 4 and 5).

\footnotetext{
${ }^{1-6}$ Department of Orthodontics, Mahatma Gandhi Dental College and Hospital, Mahatma Gandhi University of Medical Sciences and Technology, Jaipur, Rajasthan, India

Corresponding Author:Siddharth Mehta, Department ofOrthodontics, Mahatma Gandhi Dental College and Hospital, Mahatma Gandhi University of Medical Sciences and Technology, Jaipur, Rajasthan, India, Phone: +91 9886100125, e-mail: sidmehta100@gmail.com

How to cite this article: Mihani L, Mehta S, Goyal V, et al. S-clasp with Apron Spring: A Single Tooth Crossbite Correction in Mandibular Arch. J Mahatma Gandhi Univ Med Sci Tech 2019;4(3):83-85.

Source of support: Nil

Conflict of interest: None
}

\section{Discussion}

Early correction of posterior cross-bites by means of maxillary expansion has been advocated to redirect the erupting teeth into more normal positions to eliminate premature occlusal contacts and to make beneficial dentoskeletal changes during growth periods (Bell). It has been stated that posterior cross-bites appear at a fairly

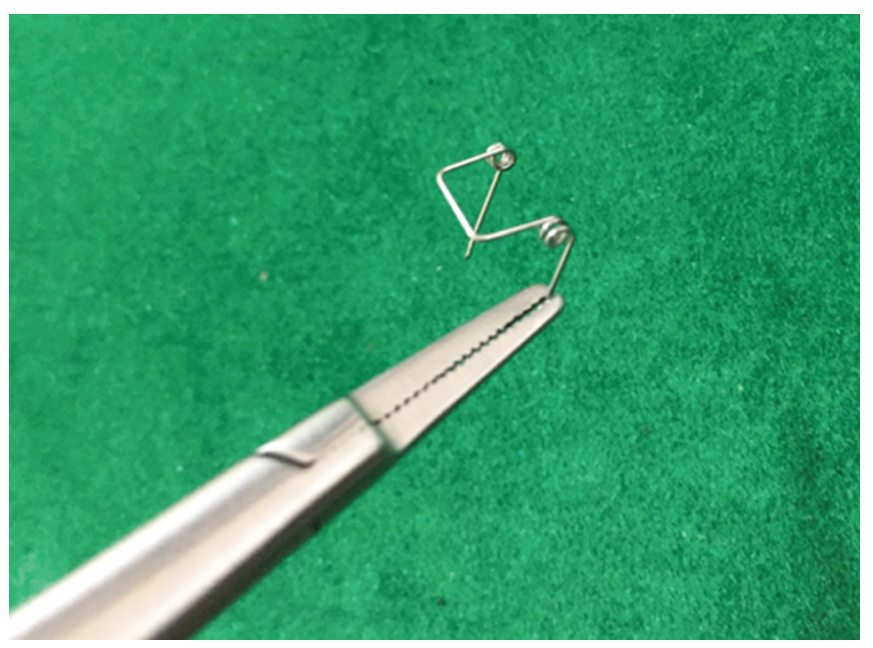

Fig. 1: Spring fabrication

o The Author(s). 2019 Open Access This article is distributed under the terms of the Creative Commons Attribution 4.0 International License (https://creativecommons. org/licenses/by-nc/4.0/), which permits unrestricted use, distribution, and non-commercial reproduction in any medium, provided you give appropriate credit to the original author(s) and the source, provide a link to the Creative Commons license, and indicate if changes were made. The Creative Commons Public Domain Dedication waiver (http://creativecommons.org/publicdomain/zero/1.0/) applies to the data made available in this article, unless otherwise stated. 
constant rate in different malocclusions and ages. This implies that this abnormality develops early and is not self-correcting (Moyers and Jay, 1959; Thilander et al.).

There are few appliances that are used for correction of crossbite in maxillary arch, i.e., quad helix and removable appliance with expansion screw.

The quad-helix appliance was made of $0.9-\mathrm{mm}$ blue elgiloy stainless steel wire (Rocky Mountain Orthodontics, U.S.A.) which was soldered to orthodontic bands adapted to the first maxillary permanent molars. Furthermore, tubes with vertical wire were soldered to the bands so that frontal cephalometric assessment of changes in the angulation of the molars on the frontal plane during treatment would be possible. Prior to cementation, the quad-helix appliance was expanded one-half of the bucco-palatal molar width in each side corresponding to an average transverse force of 300 g. The arms of the quad-helix appliance were held parallel to each other when activated. Crown torque was incorporated in the appliance so that the molar bands were kept parallel. No activation for correcting molar rotation was used.

The removable appliance has a $10-\mathrm{mm}$ screw The tube with the vertical wire that was soldered on the left and right first permanent molar bands. The removable expansion appliance used in the study. (Dentaurum, Germany), four clasps (between first permanent

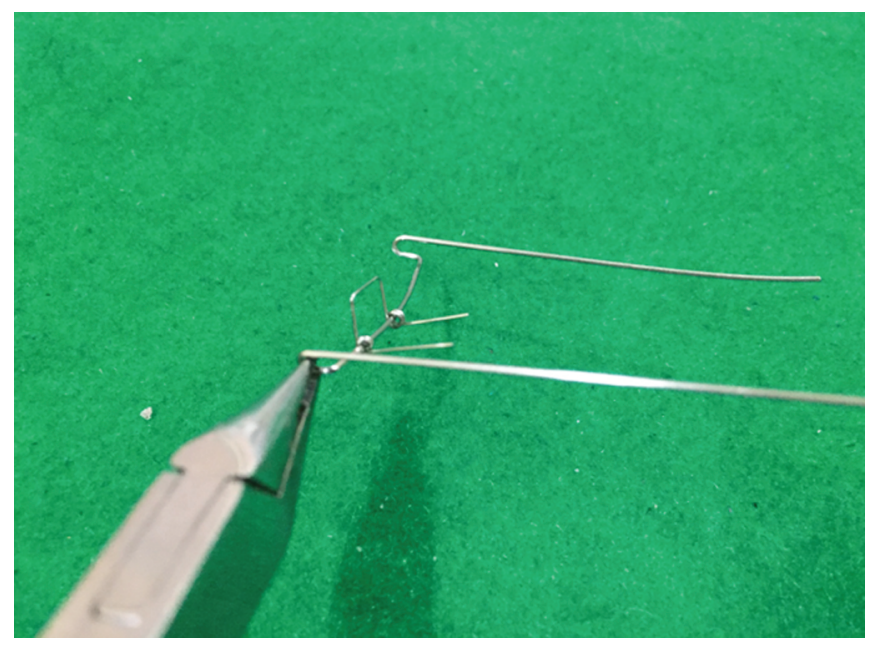

Fig. 2: Modified clasp fabrication

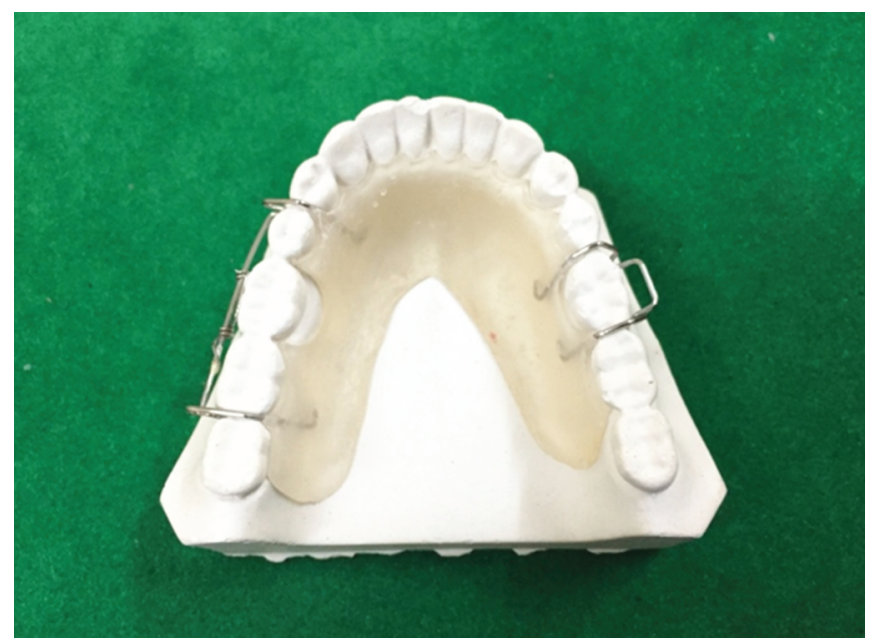

Fig. 4: Acrylization of appliance molar and second deciduous molar, and between first deciduous molar and the deciduous canine, in each side), and acrylic covering of all posterior maxillary occlusal surfaces for disarticulating the occlusion. Some acrylic was removed behind the upper incisors in order to minimize separation of these teeth during expansion. ${ }^{13}$

These appliances were used in maxillary arch to correct crossbite. In this article, we have designed a appliance for mandibular arch to correct a single tooth crossbite with is because of the bucally tipped tooth in the lower arch.

We have designed a modified clasp (named S-clasp) which is used to correct a single tooth crossbite in mandibular arch in cases in which the mandibular molar is buccally positioned. In this clasp, there is a flat bridge extending from mesial of second premolar to distal of second molar which is placed as close as possible to gingival margin. In this a 0.016 round stainless steel wire is used to form a spring which is incorporated into the clasp to correct the crossbite which can be activated accordingly.

\section{Conclusion}

This appliance is used in cases where maxillary expansion is not required to correct the crossbite. So indication for this appliance can be the crossbite that occurs because of buccally tipped mandibular molar.

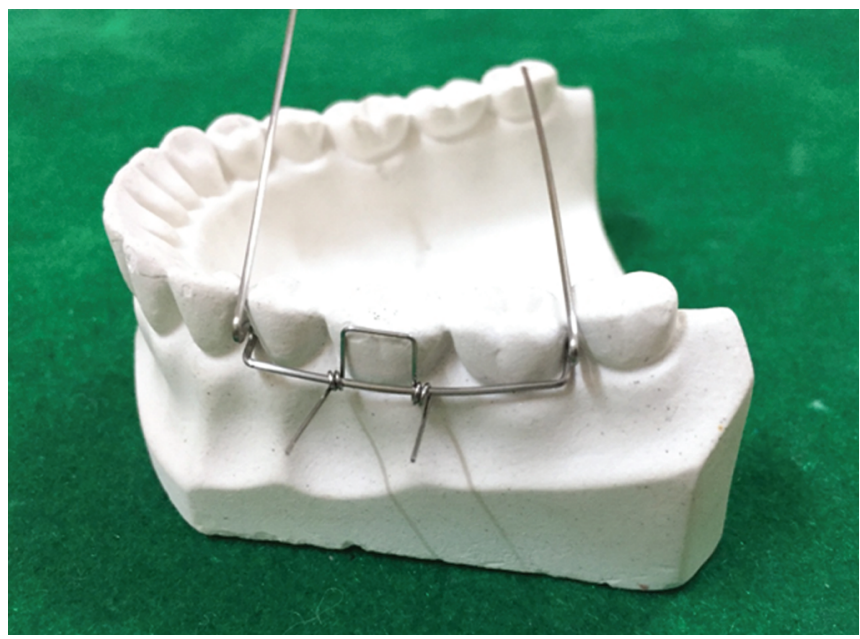

Fig. 3: Adapting fabricated clasp

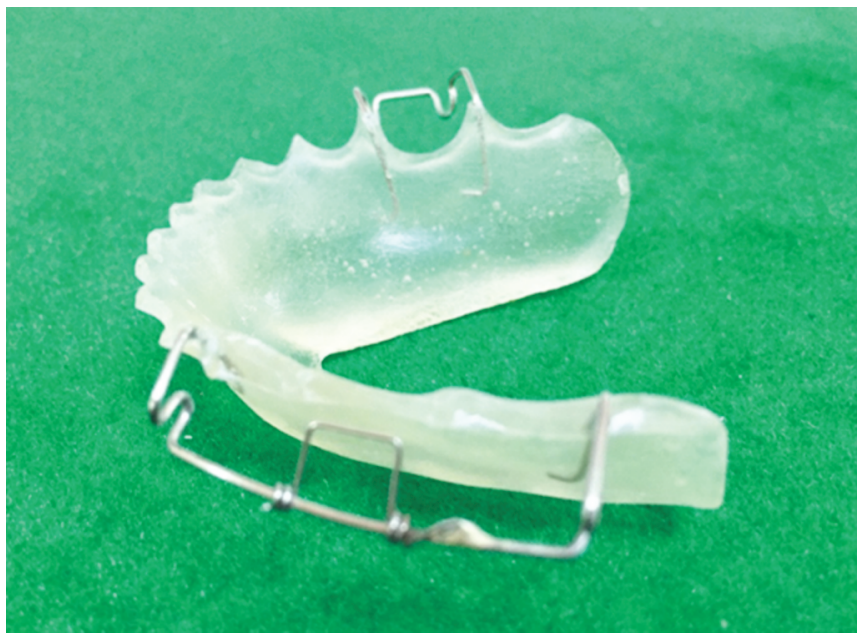

Fig. 5: Finished appliance 


\section{References}

1. Kutin G, Hawes RR. Posterior cross-bites in the deciduous and mixed dentitions. Am J Orthod 1969;56(5):491-504. DOI: 10.1016/00029416(69)90210-3.

2. Thilander B, Myrberg N. The prevalence of malocclusion in swedish schoolchildren. Scand J Dent Res 1973;81(1):12-20. DOI: 10.1111/j.16000722.1973.tb01489.x.

3. Heikenheimo K, Salmi K. Need for orthodontic intervention in fiveyear-old Finnish children. Proc Finn Dent Soc 1987;83:165-169.

4. Egermark-Eriksson I, Carlsson GE, Magnusson T, et al. A longitudinal study on malocclusion in relation to signs and symptoms of craniomandibular disorders in children and adolescents. Eur J Orthod 1990;12(4):399-407. DOI: 10.1093/ejo/12.4.399.

5. Thilander B, Wahlund S, Lennartsson B. The effect of early interceptive treatment in children with posterior cross-bite. Eur J Orthod 1984;6(1):25-34. DOI: 10.1093/ejo/6.1.25.

6. Kurol J, Berglund L. Longitudinal study and cost-benefit analysis of the effect of early treatment of posterior cross-bites in the primary dentition. Eur J Orthod 1992;1(3):173-179. DOI: 10.1093/ejo/ 14.3.173.
7. Ninou S, Stephens $C$. The early treatment of posterior crossbites: a review of continuing controversies. Dent Update 1994;21:420-426.

8. MCNamara JAJr, Turp JC. Orthodontic treatment and temporomandibular disorders: is there a relationship? part 1. Clinical studies. J Orofac Orthop 1997;58:74-89.

9. Luther F. Orthodontics and temporomandibular joint: where are we now? part 1: Orthodontic treatment and temporomandibula disorders. Angle Orthod 1998;68:295-304.

10. Godoy F, Rosenblatt A, Godoy-Bezerra J. Temporomandibular disorders and associated factors in Brazilian teenagers: a cross sectional study. Int J Prosthodont 2007;20:599-604.

11. Bell RA. A review of maxillary expansion in relation to rate of expansion and patient's age. Am J Orthod 1982;81(1):32-37. DOI: 10.1016/0002-9416(82)90285-8.

12. McNamara JA. Early intervention in the transverse dimension: is it worth the effort? Am J Orthod Dentofacial Orthop 2002;121(6):572574. DOI: $10.1067 / \bmod .2002 .124167$.

13. Boysen B, La Cour K, Athanasiou AE, et al. Three-dimensional Evaluation of dentoskeletal changes after posterior cross-bite correction by quad-helix or removable appliances. Br J Orthod 1992;19(2):97-107. DOI: 10.1179/bjo.19.2.97. 